\title{
40. VELOCITY ANISOTROPY IN CALCAREOUS SEDIMENTS FROM LEG 130, ONTONG JAVA PLATEAU ${ }^{1}$
}

\author{
Franck C. Bassinot, ${ }^{2}$ Janice C. Marsters, ${ }^{3}$ Larry A. Mayer ${ }^{4}$ and Roy H. Wilkens ${ }^{3}$
}

\begin{abstract}
During Leg 130, an intensive program of $P$-wave velocity measurements was conducted on calcareous sediments of varying induration (ranging from ooze to limestone) that cover the Ontong Java Plateau (west equatorial Pacific). The high quantity and quality of shipboard acoustical property measurements seemed to be particularly appropriate for gaining a better understanding of acoustic anisotropy in calcareous sediments. Major results can be summarized as follows:

1. In calcareous oozes, acoustic anisotropy exists even at shallow depths of burial. Values are low, ranging from $-0.5 \%$ to $3.5 \%$ and averaging $1.2 \%$. Anisotropy profiles are affected by coring disturbances, but they still roughly correlate between holes cored at a same site. There is no general increase of anisotropy with depth of burial in ooze sections. These observations imply that most of the anisotropy measured in oozes is controlled by original changes in sediment composition rather than by reorientation of anisotropic minerals or flattening of pores during burial. Given the data available, bedding lamination seems to be the most satisfactory explanation for acoustic anisotropy in calcareous oozes of Ontong Java Plateau. However, bioturbation affects the entire ooze sections cored and much of the original depositional features may have been removed. Further analysis such as scanning-electron-microscope (SEM) observations of epoxy impregnated ooze samples are necessary to test the "bedding lamination" hypothesis.

2. Ooze to chalk transition is marked by a tremendous change in the anisotropy profiles. In chalk sections the anisotropy values are higher (reaching 20\%) than in ooze sections. Most of the anisotropies are negative (horizontal $P$-wave velocities lower than vertical velocities), whereas positive values are expected. Weakly cemented chalk samples are affected by cracking when compressed between the Hamilton Frame transducers for $P$-wave measurement. Cracks occur along bedding planes during horizontal $P$-wave velocity measurements, thus leading to anomalously low horizontal $P$-wave velocities and negative anisotropies.
\end{abstract}

\section{INTRODUCTION}

In recent years, numerous studies have improved geoacoustic modeling of the deep-sea sediment column by analyzing physical properties ( $P$-wave velocity, porosity, wet-bulk density) and studying their relationships with sediment composition, depth of burial and age (Akal, 1972; Hamilton, 1974, 1980; Milholland at al., 1980; Kim et al., 1985). A small part of these efforts has been dedicated to the understanding of acoustic anisotropy in marine sediments. It has been observed that horizontal $P$-wave velocities (measured parallel to bedding) are usually higher than vertical velocities (measured perpendicular to bedding) (Bachman, 1979; Carlson and Christensen, 1977, 1979; Carlson, 1981; Kim et al., 1983; Carlson et al., 1984; Schaftenaar and Carlson, 1984). Velocity anisotropy is important for the interpretation of seismic refraction and reflection data as it affects seismic-wave propagation in the sediment column (Carlson and Christensen, 1979; Bachman, 1979; Milholland et al., 1980). Furthermore, acoustic anisotropy studies can provide information concerning sediment fabric and therefore provide valuable insights into sedimentary and diagenetic processes.

According to Hamilton's prediction (1970), acoustic anisotropy in marine sediments is primarily caused by overburden pressure that acts through reorientation of particles and pores flattening during burial. The amount of such anisotropy should be zero at the seafloor and increase with depth of burial. Johnson et al. (1977) made $P$-wave velocity measurements on surficial calcareous sediments from

\footnotetext{
'Berger, W.H., Kroenke, L.W., Mayer, L.A., et al., 1993. Proc, ODP, Sci. Results, 130: College Station, TX (Ocean Drilling Program).

${ }^{2}$ Laboratoire de Géologie du Quaternaire, CNRS-Luminy, Case 907, 13288 Marseille Cedex 9, France.

${ }^{3}$ Institute of Geophysics, School of Ocean and Earth Science and Technology, University of Hawaii, 2525 Correa Road, Honolulu, HI 96822, U.S.A.

${ }^{4}$ Ocean Mapping Group, Department of Surveying Engineering, University of New Brunswick. P.O. Box 4400, Fredericton, New Brunswick E3B 5A3, Canada.
}

Ontong Java Plateau. They did not find any clear indication of acoustic anisotropy at the seafloor level; therefore, their results confirm Hamilton's prediction. Only a limited number of studies have dealt with velocity anisotropy in uncemented deep-sea carbonates below the seafloor (e.g., Kim et al., 1983). Most anisotropy studies have been performed on chalk or limestone samples. These studies have recognized three potential causes for $P$-wave velocity anisotropy in calcareous sediments and sedimentary rocks: (1) preferred orientation of anisotropic mineral grains (Carlson and Christensen, 1979; Milholland et al., 1980); (2) alignment of cracks and elongate pores (Hamilton, 1970; Kim et al., 1983, 1985); and (3) bedding lamination (Carlson et al., 1984; Schaftenaar and Carlson, 1984; Kim et al., 1985). Much work remains to be done in testing these possible causes of acoustic anisotropy. The high quantity and quality of shipboard measurements of acoustical properties made on sediments recovered during Leg 130 seemed to be particularly appropriate for gaining a better understanding of anisotropy in calcareous pelagic sedimer.ts.

During Leg 130, nearly $4800 \mathrm{~m}$ of relatively homogeneous pelagic calcareous sediments were recovered from 16 holes drilled at five sites (803-807) on a depth transect situated in the northeastern part of the Ontong Java Plateau (Fig. 1; Kroenke, Berger, Janecek, et al., 1991). The sediments consist of Pleistocene to upper Eocene oozes and chalks made of nannofossils with varying amounts of foraminifers. Eocene to Cretaceous limestone was also drilled at Site 807. Beside $P$-wave velocity measurements performed on chalk and limestone using the "classical" Hamilton Frame, we used a new device, the digital sound velocimeter (DSV; Mayer et al., 1987) for $P$-wave velocity measurements in ooze sections. This device, used for the first time during a DSDP/ODP Leg, made it possible to accurately measure ooze $P$-wave velocities perpendicular and parallel to the core axis without disturbing the sediment. In previous DSDP/ODP Legs, one could measure ooze velocities in both directions only when sediment became stiff enough to be cut for insertion between Hamilton Frame transducers. The measurements made on weakly consolidated oozes were most likely affected by sampling disturbance. 


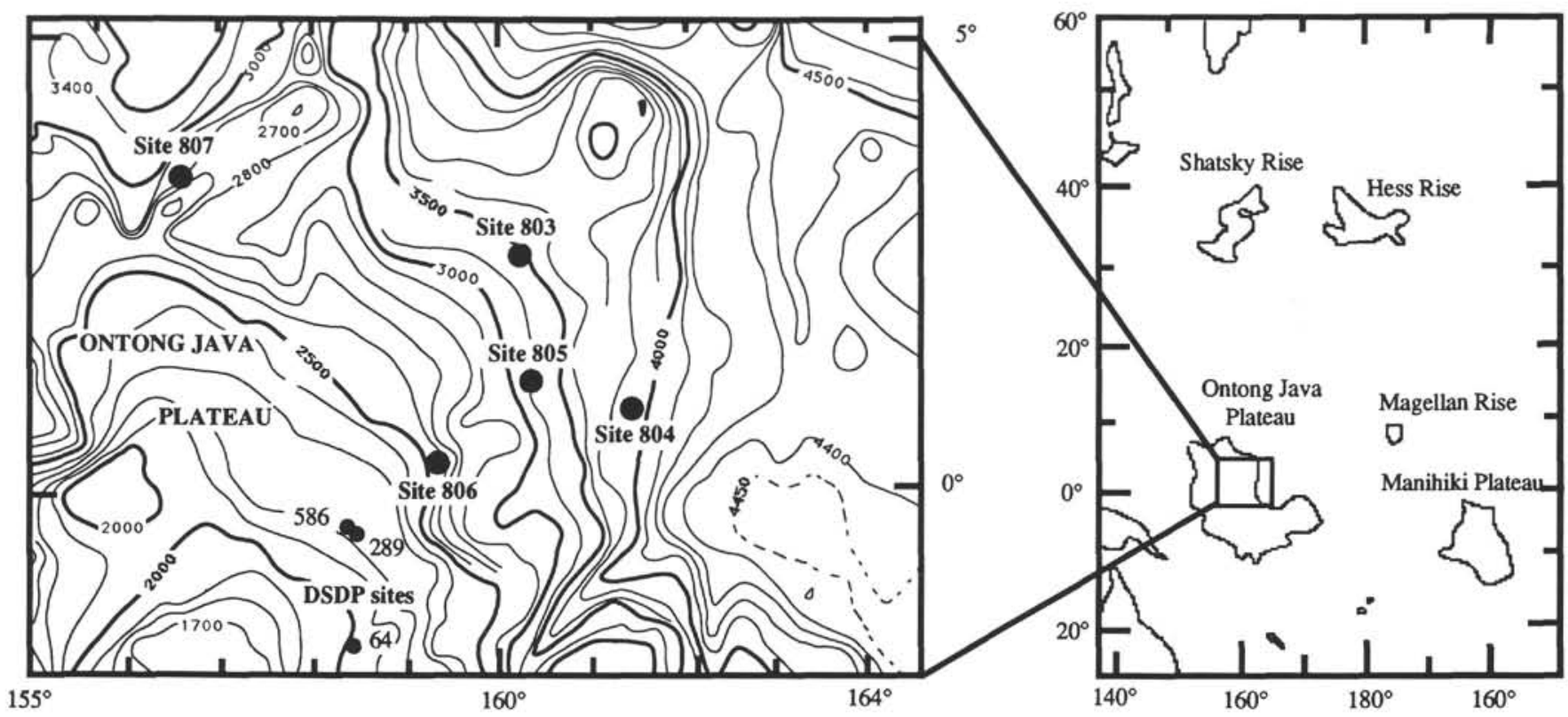

Figure 1. Locations of ODP Leg 130 and previous DSDP drilling sites on the northeastern portion of the Ontong Java Plateau. Bathymetric contours are in meters.

Using both DSV and Hamilton Frame velocity data, we have here an opportunity to study acoustic anisotropy in calcareous sediments of varying induration, ranging from ooze to limestone. Particular attention will be given to acoustic anisotropy in the ooze section.

\section{EXPERIMENTAL METHODS}

In unconsolidated sediments, $P$-wave velocities were measured using the computer-controlled digital sound velocimeter (DSV; Mayer et al., 1987). Velocity calculation is based on the accurate measurement of the traveltime of an acoustic signal between a pair of piezoelectric transducers carefully inserted within the split sediment cores. A $2-\mu$ s square wave is used to drive the transducers that have resonance frequencies of about 250 and $750 \mathrm{kHz}$. The impulse and the received signal are digitized using a Nicolet 320 digital oscilloscope and transferred to the microcomputer for processing. The DSV software selects the first arrival and calculates the velocity. The full waveform is stored for later calculation of attenuation. Four transducers are used; two of them, separated by approximately $7 \mathrm{~cm}$, measure the vertical $P$-wave velocity (along the core axis), and the other two, separated by approximately $3.5 \mathrm{~cm}$, measure the horizontal velocity (parallel to bedding). The transducers are firmly fixed at one end on a steel plate so that their separation remains constant during velocity measurements. Thermistors in the transducer probes monitor temperatures during measurements. Periodically, the separation of the transducers is precisely evaluated by running a calibration procedure in distilled water. Velocity measurements are considered to be accurate within $\pm 2 \mathrm{~m} / \mathrm{s}$.

The Hamilton Frame velocimeter (Boyce, 1976) was used to measure compressional wave velocities at $500 \mathrm{kHz}$ in discrete samples, when induration made it difficult to insert DSV transducers without sample disturbance, and in lithified sediments where insertion became impossible. Samples were carefully cut using a double-bladed diamond saw to obtain parallel faces. Sample thickness was measured directly from the velocimeter-frame lead screw. Zero traveltimes for the velocity transducers were estimated by linear regression of traveltime vs. distance for a series of aluminium and lucite standards. Filtered seawater was used between the sample and the transducers to improve acoustic contact. The DSV oscilloscope and processing software were used to digitize waveforms, calculate velocities, and store waveforms for later attenuation calculations.
Following Carlson and Christensen (1979), velocity anisotropy is expressed as a percentage of the velocity difference to the mean velocity:

$$
A=200 \cdot\left(V_{h}-V_{v}\right) /\left(V_{h}+V_{v}\right),
$$

with $V_{h}$ being the horizontal $P$-wave velocity (parallel to bedding), and $V_{v}$ the vertical velocity (perpendicular to bedding).

\section{DISCUSSION OF RESULTS}

The anisotropy profile from Site 807 (Fig. 2) shows the typical shape of profiles recorded in sedimentary sections cored during Leg 130. As for the other sites, the anisotropy profile is marked by an unexpected major change at about the ooze/chalk transition. At this level, anisotropy values change from low (around 1\%), usually positive values exhibiting low-amplitude variations within the ooze section to much more variable and higher absolute values (up to $20 \%$ ) in the chalk and the limestone section. The most puzzling result is that the chalk interval is dominated by negative anisotropy values (vertical velocities higher than horizontal velocities) whereas positive values were expected. Because of the clear difference between anisotropy in ooze, on the one hand, and anisotropy in chalk and limestone, on the other hand, we will discuss the ooze records and the chalk/limestone records separately.

\section{VELOCITY ANISOTROPY IN CALCAREOUS OOZES}

\section{Introduction: Intervals of Study}

In the ooze sections cored during Leg 130, increasing sediment consolidation with depth of burial and onset of cementation lead to increasing sediment stiffness. Beginning at a certain level (depth varying from one site to another), the sediment became so stiff that we created small fractures along the bedding planes when we inserted the DSV transducers. These fractures made it sometimes difficult to transmit and receive the acoustic signal for vertical $P$-wave measurements and probably also affected the sonic velocity. Analysis of velocity anisotropy in oozes must be conducted above a depth at which induced fracturing is observed. Velocity anisotropy will be discussed in the upper $160 \mathrm{mbsf}$ at Site $803,140 \mathrm{mbsf}$ at Site 804, $210 \mathrm{mbsf}$ at Site 805, $250 \mathrm{mbsf}$ at Site 806, and $250 \mathrm{mbsf}$ at Site 807. 


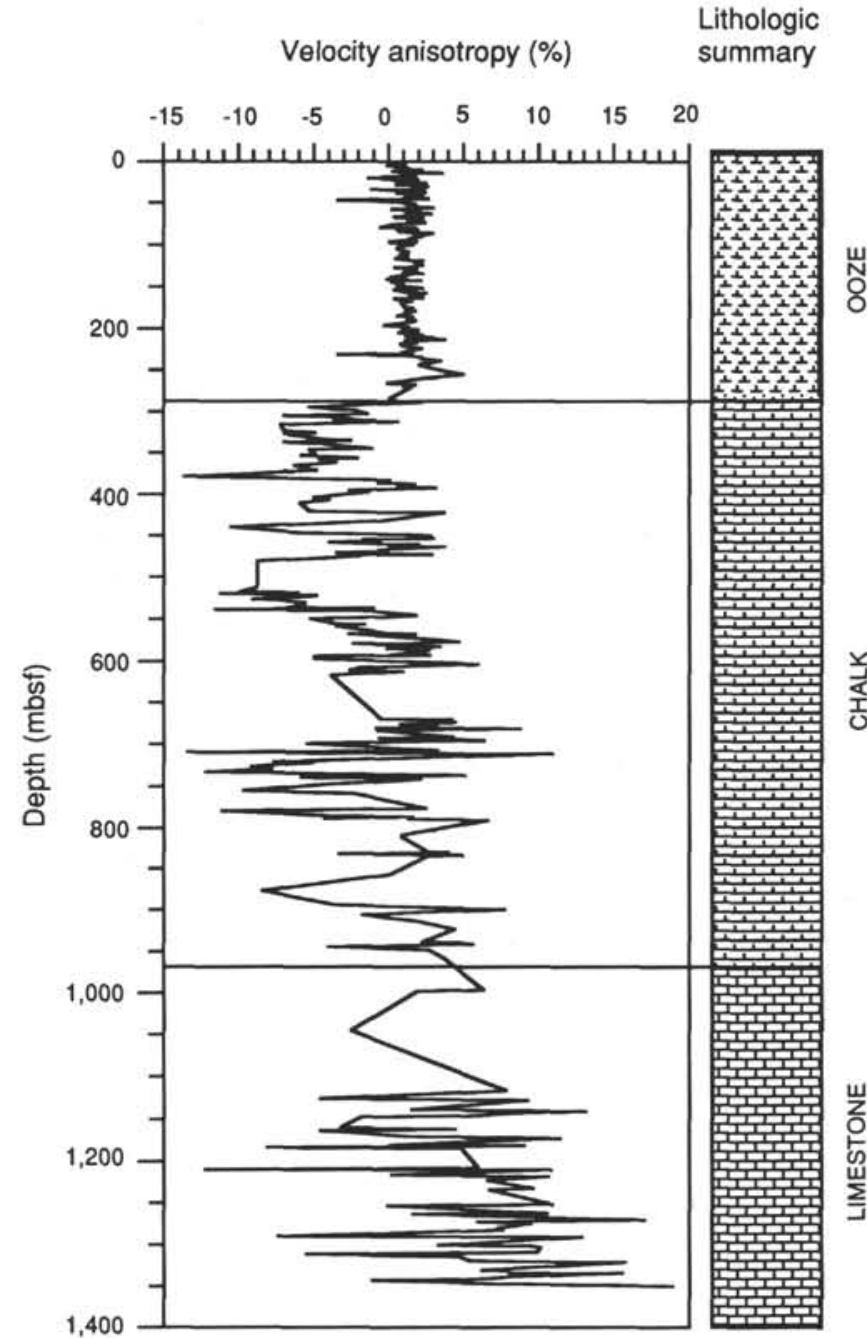

Figure 2. Anisotropy vs. depth (data from Hole 807A and 807C) and simplified lithologic summary, Site 807.

Profiles of the velocity anisotropy for Sites $803,804,805$, and 806 are presented in Figures 3-7. In Figure 7, smoothed anisotropy profiles of Holes $806 \mathrm{~B}$ and $806 \mathrm{C}$ make it possible to identify general trends and main fluctuations.

\section{Results}

The $P$-wave velocities measured in calcareous oozes range from 1510 to $1650 \mathrm{~m} / \mathrm{s}$. Velocity anisotropies are low, ranging from $-0.5 \%$ to $3.5 \% \pm 0.3 \%$ and averaging $1.2 \%$. Anisotropy evolution with depth of burial is different from site to site. Site 803 shows a generally decreasing velocity anisotropy with depth of burial (Fig. 3); Site 805 shows no major trend over the entire depth range studied (Fig. 5); Site 806 (Figs. 6 and 7) shows a weak general increase of anisotropy with depth. Site 804 (Fig. 4) shows a strong increase of anisotropy with depth to $120 \mathrm{mbsf}$ and then an apparent decrease. Thus, it appears that no general pattern exists in velocity anisotropy profiles in Leg 130 oozes. Instead, evolution of anisotropy with depth of burial probably reflects local changes in the sediment column.

First-order fluctuations in anisotropy profiles may be correlated between holes drilled at a same site (Figs. 3-7). Site 804 shows the clearest evidence of such correlations (Fig. 4). At Site 805 (Fig. 5), no clear common trend is noticed in the uppermost 100 mbsf of Holes $805 \mathrm{~B}$ and $805 \mathrm{C}$, but a marked parallel increase of anisotropy

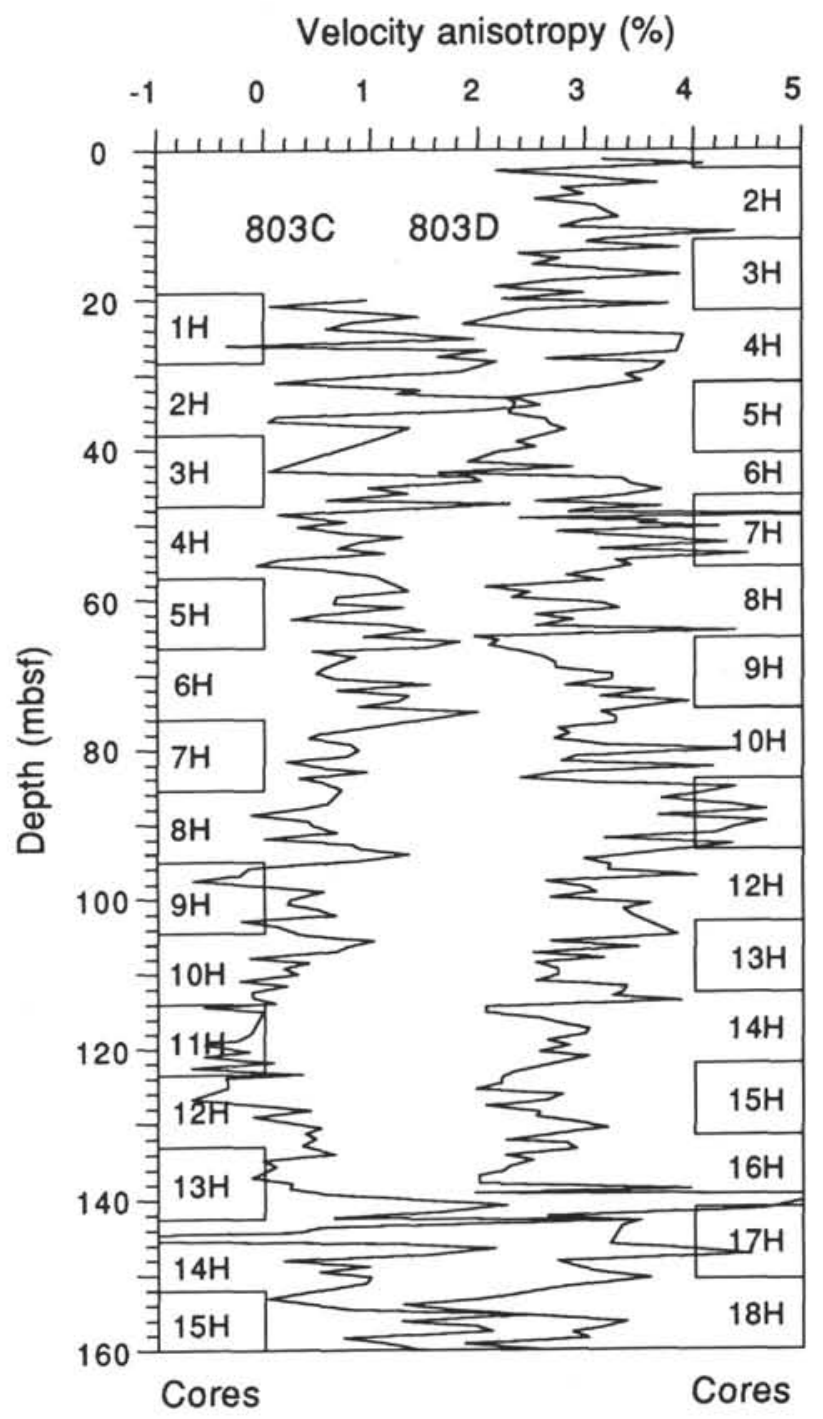

Figure 3. Velocity anisotropy vs. depth in ooze section, Holes $803 \mathrm{C}$ and $803 \mathrm{D}$. Profile for Hole $803 \mathrm{D}$ is offset by $2 \%$.

values occurs between 100 and 120 mbsf. This increase is followed, below $120 \mathrm{mbsf}$, by a decrease downhole of anisotropy values from both holes. At Site 806, anisotropy values increase slightly with increasing depth of burial between the seafloor and $160 \mathrm{mbsf}$ (Figs. 6 and 7). At 160 mbsf, anisotropy values reach a plateau at Hole $806 \mathrm{C}$, but they seem to decrease slightly with depth of burial at Hole 806B.

At smaller scales, many excursions from these general trends can also be correlated between holes. For instance, the same interval of high anisotropy values exists between 0 and approximately $40 \mathrm{mbsf}$ in Holes 806B and 806C (Figs. 6 and 7).

The differences between the anisotropy profiles for the holes from the same site may be the result of coring disturbances. The strongest evidence of coring disturbance effects on anisotropy appear as anomalously low or high values measured at the core ends where disturbance is likely to be greatest. See, for example, anisotropy profile at Hole 806B (Fig. 6). There is also evidence that coring disturbance is not always restricted to core ends but may affect acoustical properties of the sediment within a core. For instance, anisotropy profiles in Cores 130-805B-10H and -11H (Fig. 5) show the same anomalous pattern, with low values recorded in more than the upper half part of these cores, increasing abruptly downcore. Sediment disturbances occurring within a core have been described 


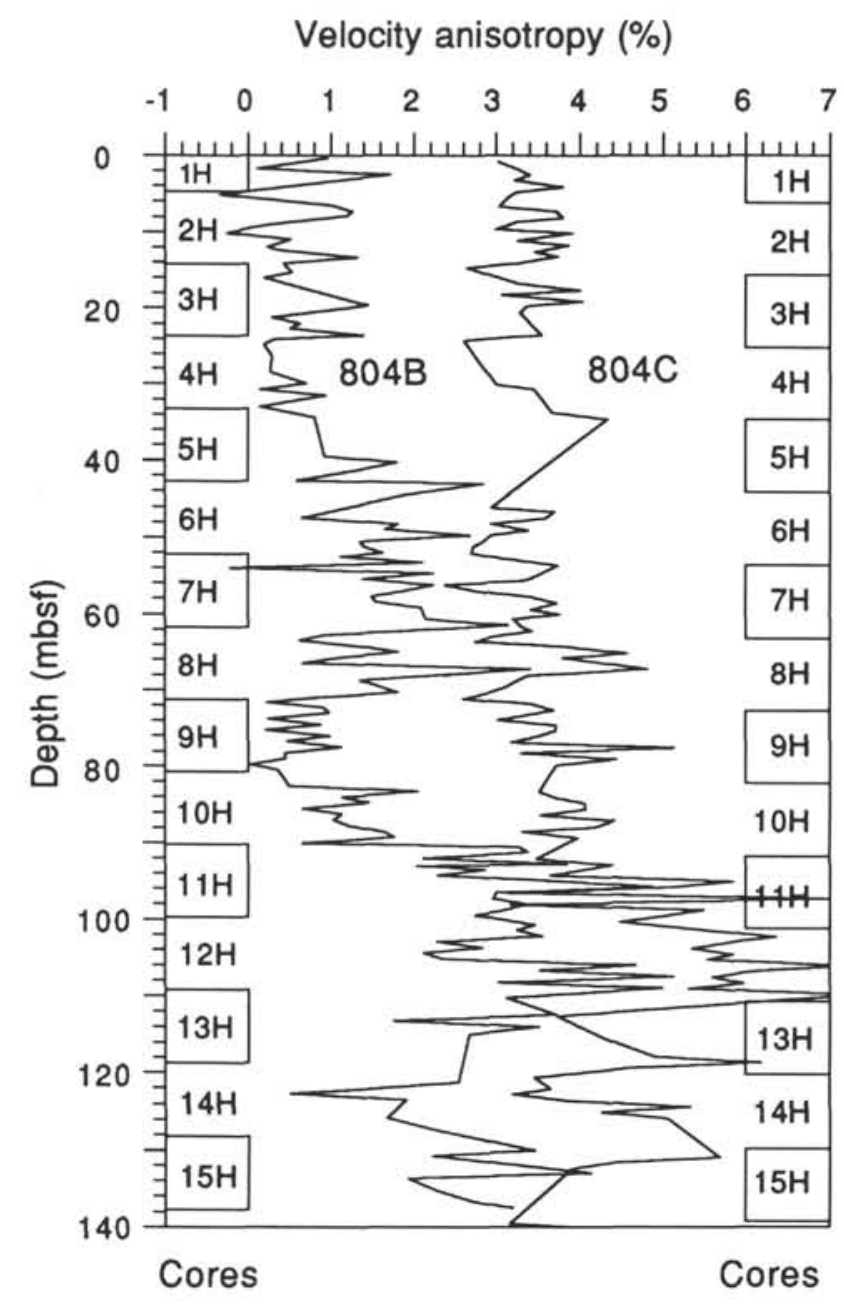

Figure 4. Velocity anisotropy vs. depth in ooze section, Holes 804B and 804C. Profile for Hole $804 \mathrm{C}$ is offset by $3 \%$.

previously by scientists on Leg 86 (Heath, Burckle, et al., 1985) and reviewed by Ruddiman et al. (1987). Given these observations, it is the authors' contention that coring disturbance greatly reduces our ability to correlate anisotropy profiles between holes drilled at a same site. Anisotropy profiles might be actually more strongly correlated than they appear to be. Following this hypothesis, we shall consider that there is a good relation between anisotropy and lithology, whatever the processes involved to explain this anisotropy.

In calcareous oozes cored during Leg 130, anisotropies appear to be controlled mainly by the amplitude of horizontal $P$-wave velocity changes. Linear regression of horizontal $P$-wave velocity against velocity anisotropy lead to $r^{2}$ coefficients ranging from 0.64 to 0.85 (Fig. 8), whereas regression coefficients of vertical $P$-wave velocity against anisotropy are very low (always $<0.4$ ). The dominant effect of horizontal velocity on anisotropy can be readily appreciated when considering that horizontal velocity shows larger amplitude changes than vertical velocity. $V_{h}$ varies about $\pm 70 \mathrm{~m} / \mathrm{s}$ around its average value whereas $V_{v}$ only varies about $\pm 40 \mathrm{~m} / \mathrm{s}$ around its average value.

Changes in horizontal $P$-wave velocity profiles are mimicked by vertical $P$-wave velocity changes so that anisotropy usually increases with increasing $P$-wave velocity and decreases with decreasing velocity (Figs. 9 and 10). The question is: what is controlling $P$-wave velocity changes in Ontong Java Plateau sediments? Johnson et al. (1977) and Hamilton et al. (1982) have shown that $P$-wave velocity in Ontong Java Plateau sediments is closely linked to percent coarse
Velocity anisotropy (\%)

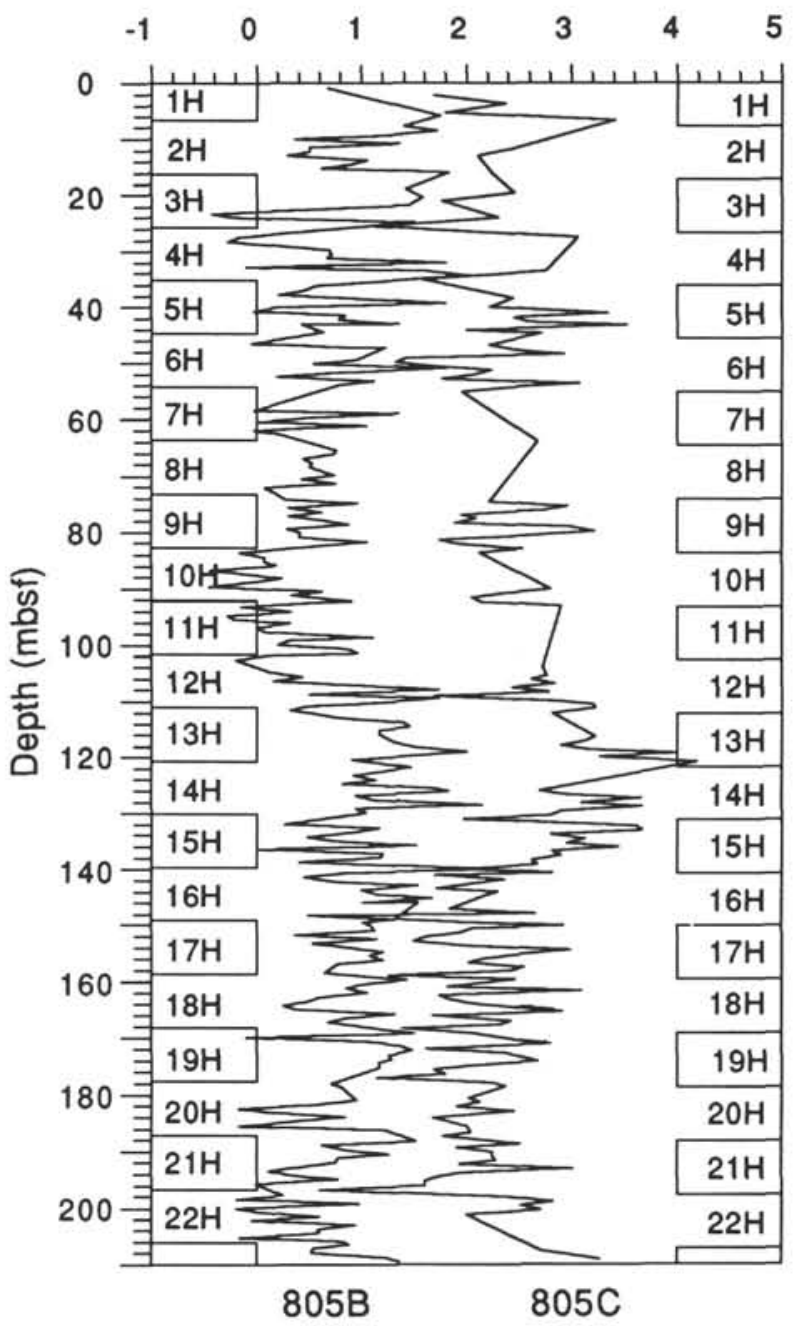

Figure 5. Velocity anisotropy vs. depth in ooze section, Holes 805B and $805 \mathrm{C}$. Profile for Hole $805 \mathrm{C}$ is offset by $2 \%$.

fraction and to mean grain size. We measured the percent sand fraction of samples from Hole $807 \mathrm{~A}$ by carefully washing sediment on a $63-\mu \mathrm{m}$ mesh sieve. We found a correlation between $P$-wave velocities and percent sand fraction. Nevertheless, the correlation between velocity anisotropy and percent sand fraction was not as good as expected $\left(r^{2}\right.$ $=0.46$ ). At Site 806, however, major excursions in the profile of mean grain size (shipboard measurements) do appear to be reflected by fluctuations in the anisotropy profile (Fig. 11). This observation may not apply to other sites (especially for deeper sites), and we are aware of the importance of performing more analyses for understanding the relationship between lithology, $P$-wave velocity, and velocity anisotropy in Ontong Java Plateau sediments. Based on the few observations made above, however, we will propose a preliminary interpretation of the velocity anisotropy observed at Leg 130 drill sites.

\section{Possible Causes for Acoustic Anisotropy in Calcareous Oozes from Ontong Java Plateau}

Potential causes for acoustic anisotropy in aggregates are preferred orientation of anisotropic mineral grains, preferred orientation of pores and cracks, and bedding (Bachman, 1979; Carlson and Christensen, 1977, 1979; Milholland et al., 1980; Carlson, 1981; Kim et al., 1983, 1985; Carlson et al., 1984; Schaftenaar and Carlson, 
Velocity anisotropy (\%)

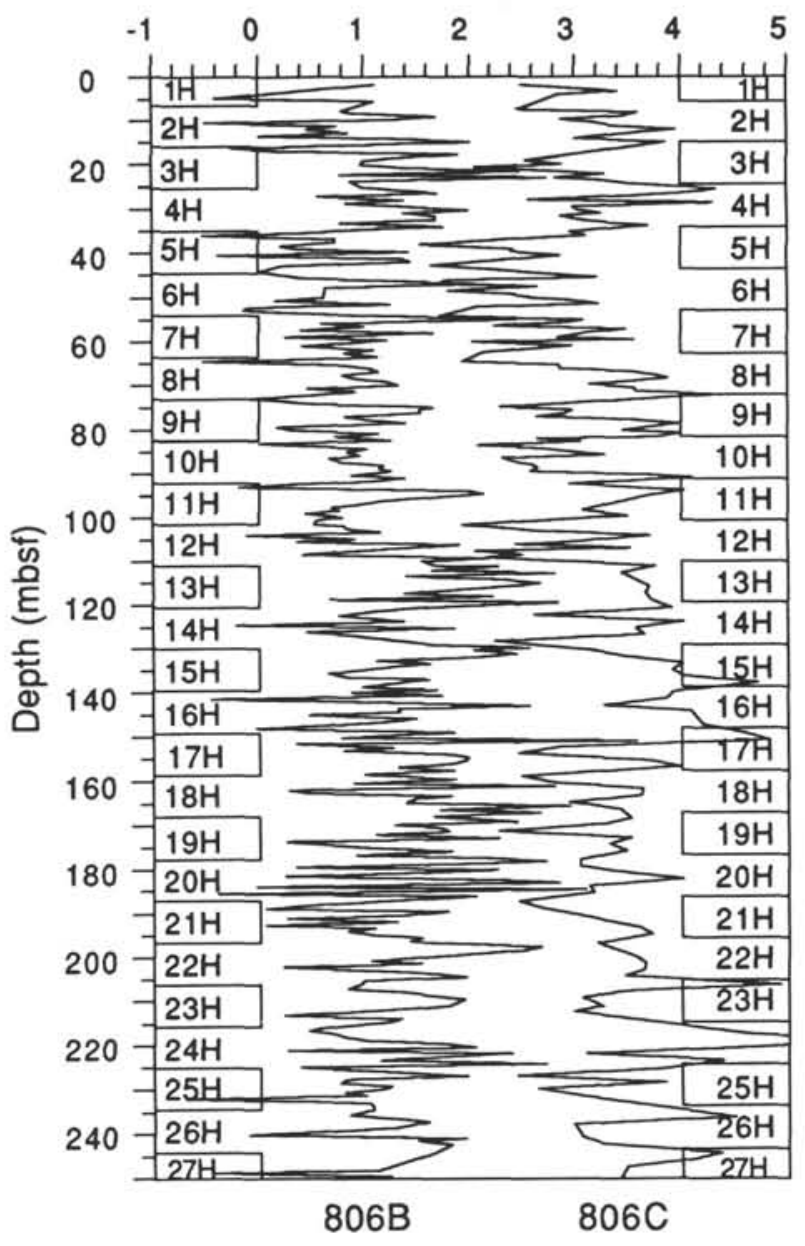

Figure 6. Velocity anisotropy vs. depth in ooze section, Holes 806B and 806C. Profile for Hole $806 \mathrm{C}$ is offset by $2 \%$.

1984). In the following discussion, we will try to determine which of these mechanisms might be the principal cause for acoustic anisotropy measured in calcareous oozes from Ontong Java Plateau during Leg 130.

\section{Mineral Orientation}

In ultramafic and metamorphic rocks, numerous authors have shown that acoustic anisotropy can be explained by preferred orientation of anisotropic minerals (Crosson and Lin, 1971; Baker and Carter, 1972; Brocher and Christensen, 1990). Calcite is a highly anisotropic mineral in which the $P$-wave velocity parallel to the $c$-axis is $5.6 \mathrm{~km} / \mathrm{s}$ whereas $P$-wave velocity perpendicular to the $c$-axis is $7.4 \mathrm{~km} / \mathrm{s}$ (Dandekar, 1968). Carlson and Christensen (1979) and Milholland et al. (1980) suggested that anisotropy in calcareous sediments is linked to preferred orientation of calcite with a concentration of $c$-axis perpendicular to bedding. In their models, calcite orientation is explained by the preferred orientation of calcareous microfossils during compaction and diagenetic processes. However, more recent studies made on indurated calcareous sediments have shown that preferred orientation of calcite does not contribute significantly to anisotropy. In deeply buried chalk samples (about 1,000 mbsf), calcite $c$-axis are only weakly concentrated perpendicular to bedding and this preferred orientation only account for less than one quarter of the total anisotropy measured (Carlson et al., 1984; Schaftenaar and Carlson, 1984).

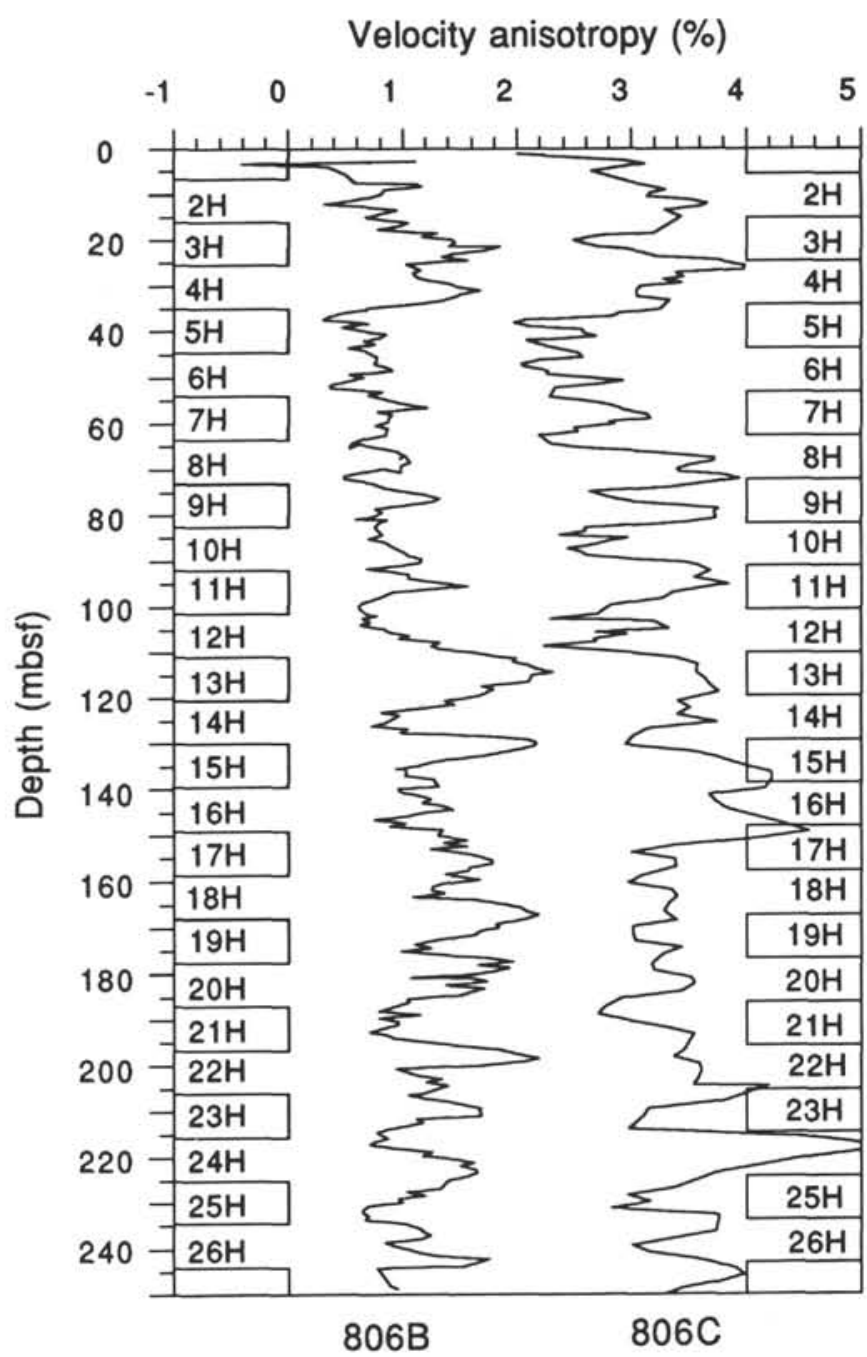

Figure 7. Smoothed anisotropy vs. depth, ooze section from Holes 806B and $806 \mathrm{C}$. Data were smoothed by a running average over $3-\mathrm{m}$ intervals. Profile for Hole $806 \mathrm{C}$ is offset by $2 \%$.

We did not measure the degree of preferred mineral orientation in ooze samples from Leg 130. However, anisotropy was measured even at shallow depth of burial (tens of meters) where consolidation processes could not have lead to important reorientations of sediment constituents. Furthermore, there is no indication of a generally increasing anisotropy with depth of burial at Leg 130 sites (Figs. 3-7). At Site 803 (Fig. 3), on the contrary, anisotropy tends to decrease with depth of burial. Based on these observations as well as those of Carlson et al. (1984) and Schaftenaar and Carlson (1984), we conclude that preferred orientation of calcite does not contribute significantly to the anisotropy measured in calcareous oozes during Leg 130.

\section{Elongate Pores}

Anisotropy may be the result of the shape and orientation of pores (Nur, 1971). However, if pore geometry was the main cause of anisotropy at Leg 130 sites, we should expect a progressive increase of anisotropy with depth of burial as pores tend to flatten and align horizontally with increasing confining pressure. As seen above, we only found indications of generally increasing anisotropy with depth of burial at Site 804 and 806 (Figs. 4, 6, and 7). At Site 803, anisotropy tends to decrease with depth of burial. This indicates that shape and orientation of pores are probably not a main cause of acoustic anisotropy measured in ooze sections during Leg 130 . 


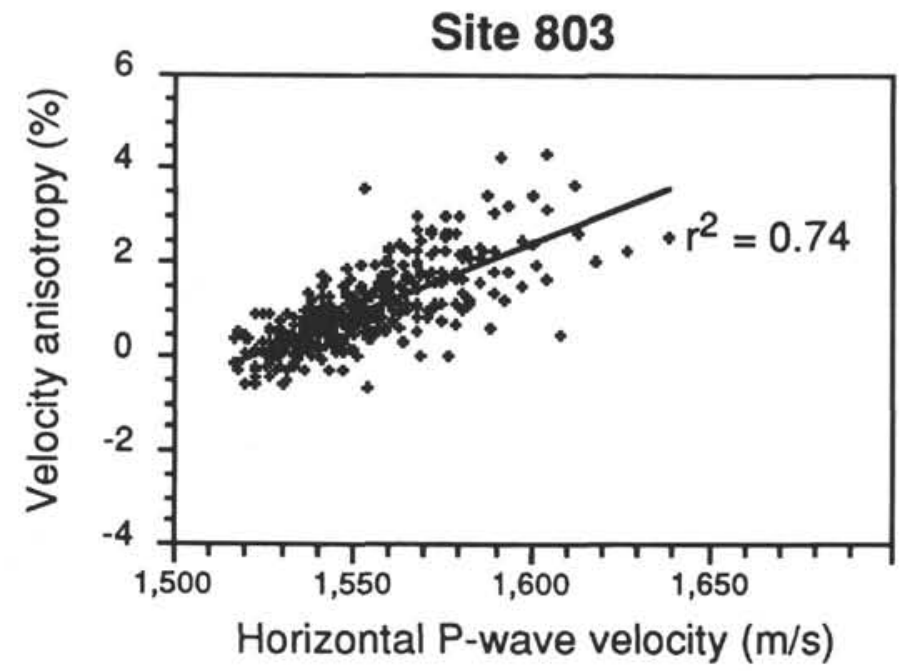

Site 805

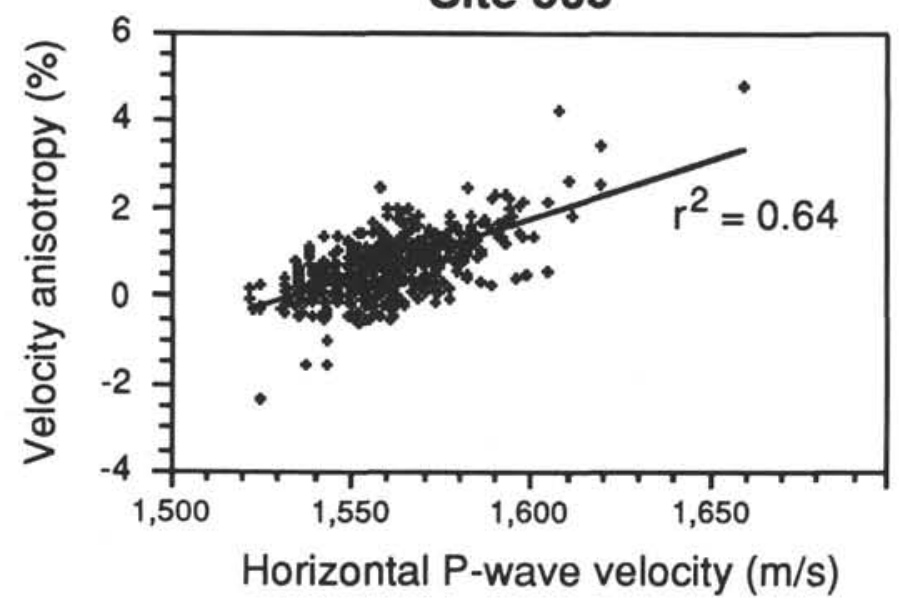

Site 804

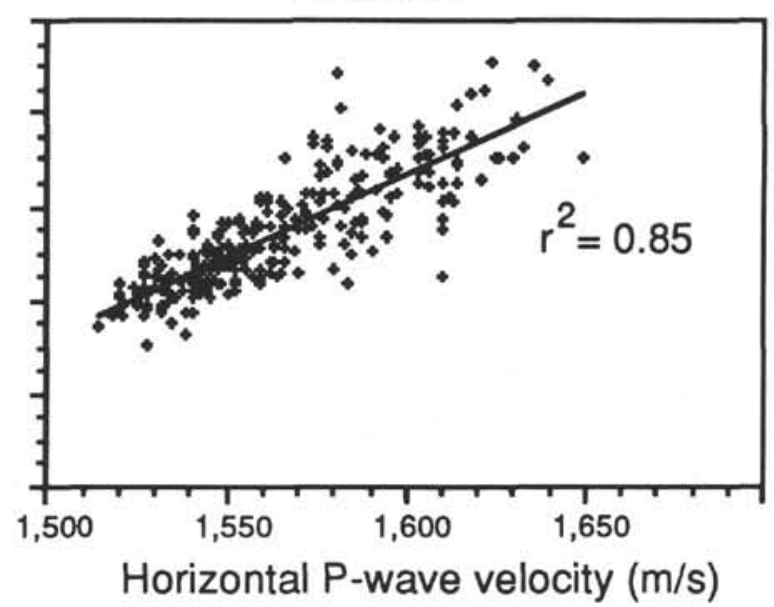

Site 806

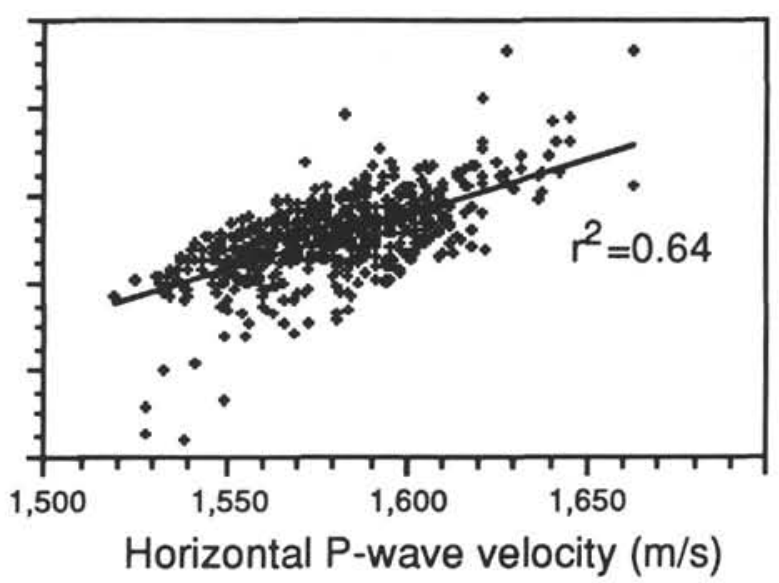

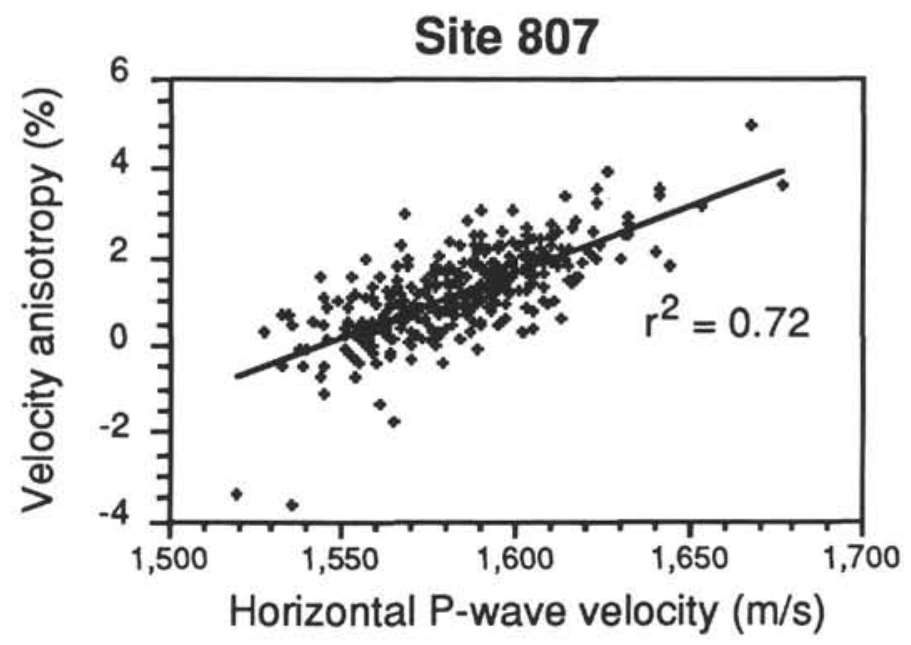

Figure 8 . Plots of velocity anisotropy vs. horizontal $P$-wave velocity in ooze sections, Sites $803,804,805,806$, and 807 . Linear regression lines are displayed with their $r^{2}$ coefficients. 


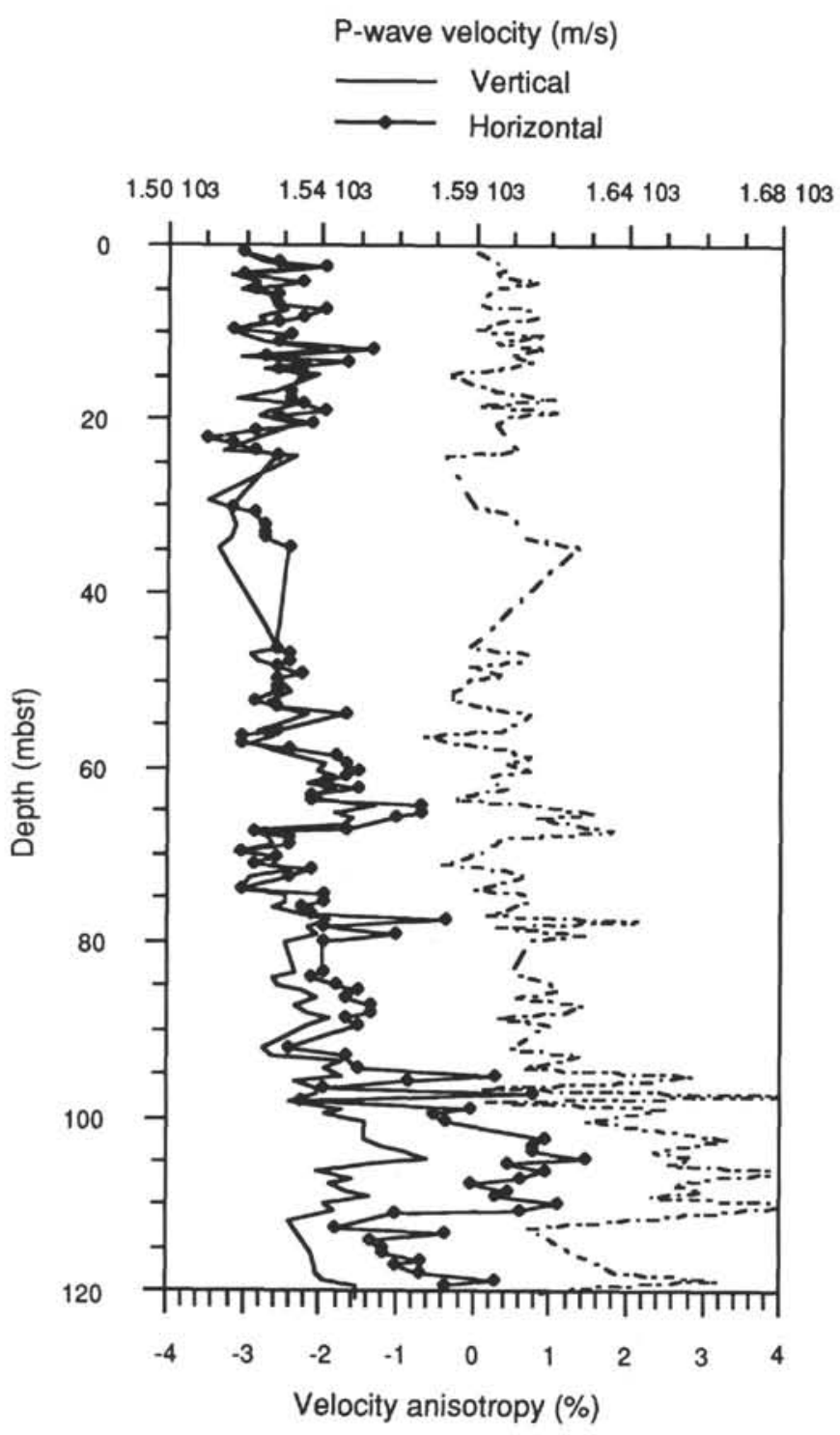

Figure 9. Horizontal and vertical $P$-wave velocity vs. depth and velocity anisotropy vs. depth, ooze section, Hole $804 \mathrm{C}$.

\section{Cracks}

When a sample is taken from a borehole and brought to shipboard laboratory conditions, the removal of overburden, and thus the stress release during core recovery, may open small cracks parallel to bedding planes. These fine cracks tend to reduce $P$-wave velocity in the vertical direction.

Urmos et al. (this volume), by comparing laboratory and well-log measurements, have shown that porosity values measured in laboratory are slightly higher than in-situ values. This porosity discrepancy is not much greater than $1 \%-2 \%$ and is remarkably constant over a great range of depth. Small cracks may account for a part of this difference between in-situ and laboratory porosity values and account therefore for acoustic anisotropy.

Because anisotropy increases with increasing velocity (Figs. 9 and 10 ), cracking should be more pronounced in intervals where high $P$-wave velocities are measured. Johnson et al. (1977) found a good relationship between high $P$-wave velocity and high percent of coarse grain fraction. As seen above, we can correlate some of the major

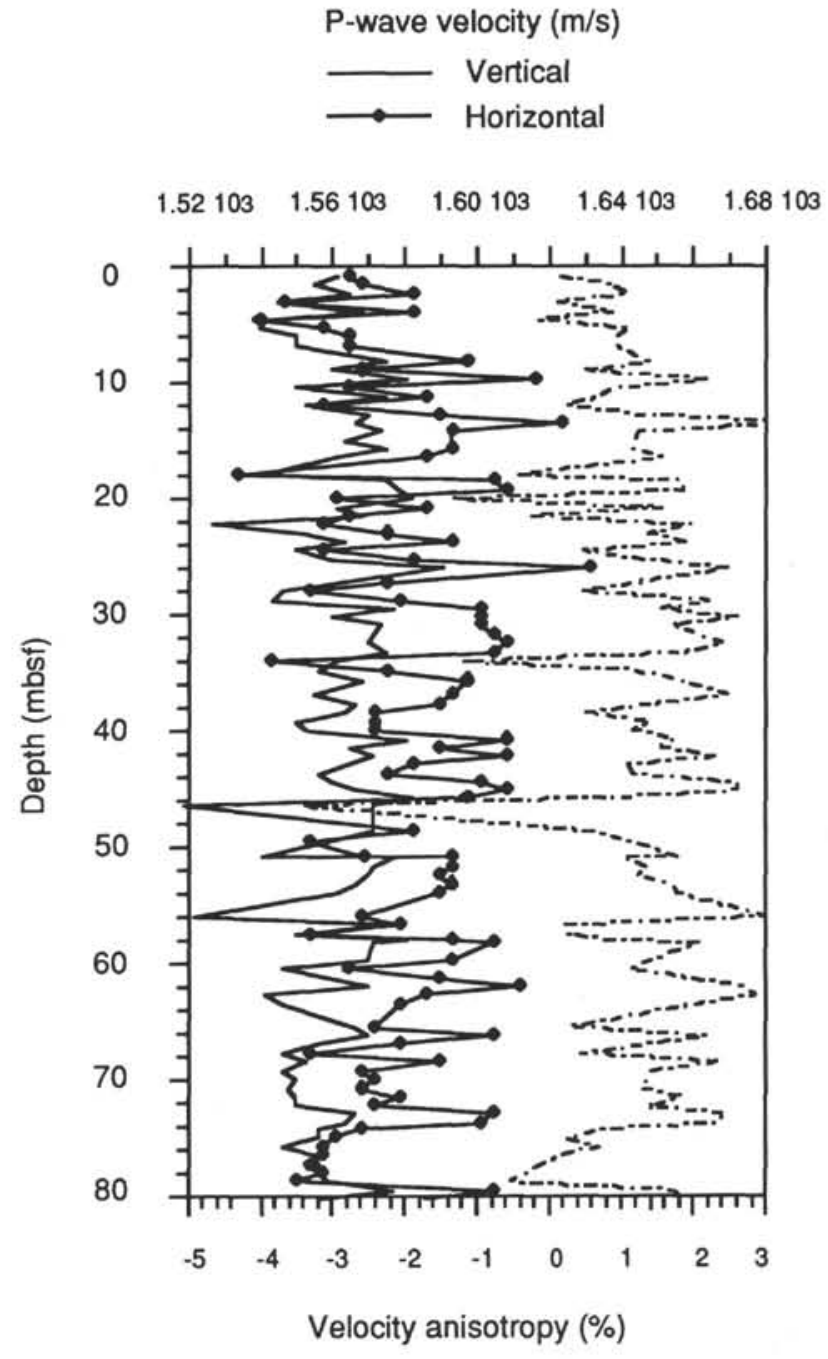

Figure 10 . Horizontal and vertical $P$-wave velocity vs. depth and velocity anisotropy vs. depth, ooze section, Hole 807A.

features of anisotropy and mean grain size profiles at Site 806 (Fig. 11). At that site, if we try to explain anisotropy through crack formation, our conclusion is that the coarse fraction content of a sediment controls its sensitivity to fracturing. Increasing percent of coarse fraction probably reduces cohesion of the sediment (cohesion being mostly due to forces acting between small sized particles), making this sediment more sensitive to cracking during removal of overburden pressure.

We can argue against this "crack model," however. Velocity anisotropies were measured even at shallow depth of burial where effective stress release is low and has probably little effect on sediment fabric (see, e.g., Site 806; Figs. 6 and 7). Other measurements made by the authors on undisturbed calcareous sediments cored with a conventional "giant" piston corer (unpubl. data) confirm that anisotropy exists in the upper few meters of sediment where crack formation is probably limited. In conclusion, if cracks account for part of the velocity anisotropy measured in the deepest buried samples at Leg 130 sites, they cannot be the only cause for anisotropy.

\section{Bedding}

In a horizontally layered medium, horizontal $P$-wave velocity $\left(V_{h}\right)$ is the fastest layer velocity whereas the vertical $P$-wave velocity 
Mean grain size $(\mu \mathrm{m})$

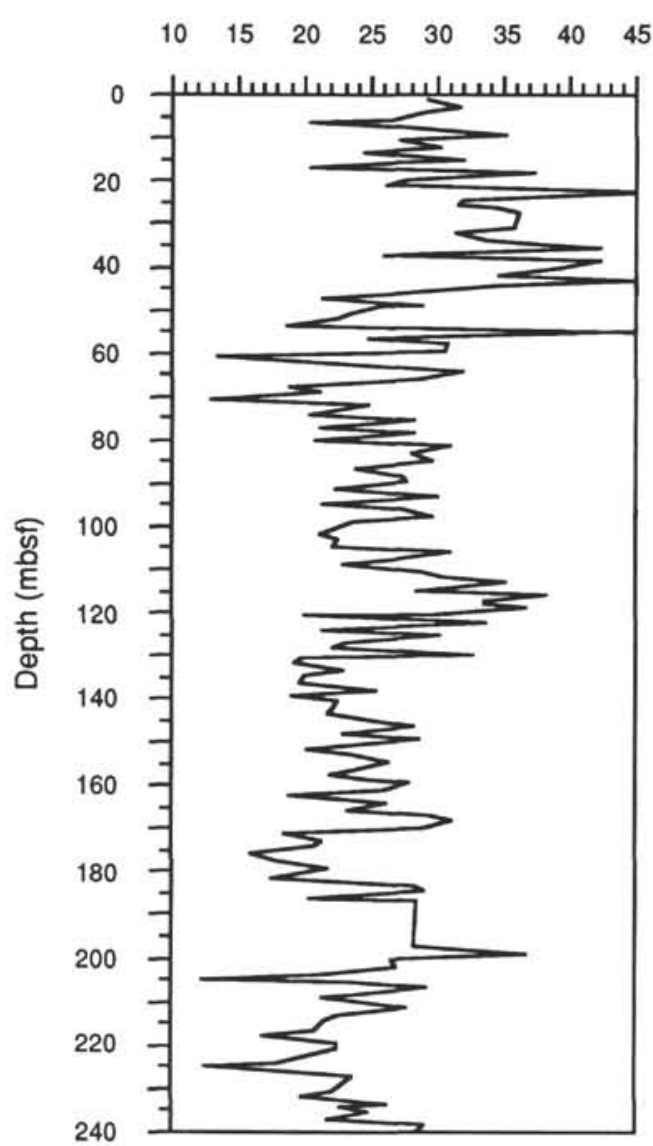

Velocity anisotropy (\%)

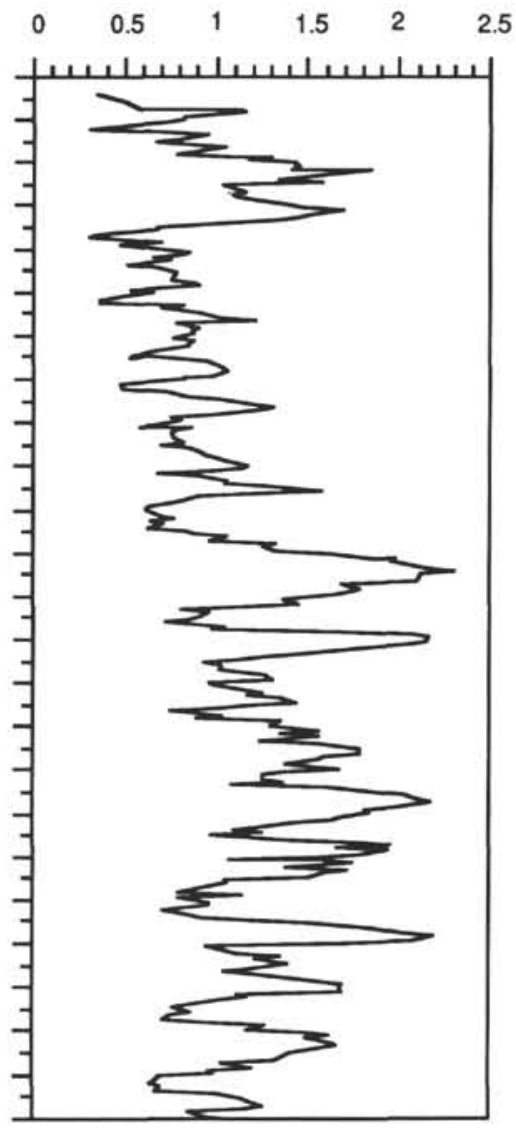

Figure 11. Smoothed velocity anisotropy vs. depth and mean grain size vs. depth, ooze section, Hole 806C.

$\left(V_{v}\right)$ is the average velocity of all layers (Kim et al., 1985). According to Carlson et al. (1984), bedding in chalks and limestones must be regarded as the principal cause for acoustic anisotropy. The present authors regard this bedding as "compositional layering" (i.e., alternating layers of different mineralogical composition). Consequently, such bedding cannot occur in a single-component system; at least one mineral other than calcite must be present (generally clay in marine sediments).

In oozes cored during Leg 130, calcite is the dominant mineral and only a few occurrences of macroscopic bedding were reported by sedimentologists (Kroenke, Berger, Janecek, et al., 1991). Most of the laminations seen in the ooze sections are liesegang color bands caused by redox fluctuations. Therefore, there should not be any anisotropy caused by bedding in the sense of Carlson et al. (1984).

Smear slide observation of calcareous limestone samples from Hole $807 \mathrm{C}$ has shown, however, that coarse particles (foraminifers) tend to align in thin layers in many cases (B. Sliter, pers. comm., 1991). There is a possibility that these layers were produced by sediment reorganization during consolidation processes, but we rather think that many of these layers represent depositional features. These layers may therefore exist in the ooze sections, and we suggest that part of the acoustic anisotropy may be produced by the alternation, at small scale, of those layers having different composition in terms of particle size and shape (alternation of foraminiferrich/nannofossil-rich layers, for instance).

At present, bedding seems to be the most satisfactory cause for anisotropy as it does not depend on depth of burial and can account, therefore, for velocity anisotropy measured in the top of ooze sections. However, all sediments recovered during Leg 130 were slightly to heavily bioturbated (Kroenke, Berger, Janecek, et al., 1991). Some of the original bedding may be preserved in weakly bioturbated sections, but there is every chance that depositional layers are absent in heavily bioturbated sections. This would imply that we have to look for another explanation to account for anisotropy in heavily bioturbated sections. We are planning to study epoxy impregnated ooze samples for a better understanding of sediment fabric and effects of bioturbation. Important points of this study will be (1) whether or not microscopic depositional layering exists and how much of the original layering is preserved after bioturbation takes place; and (2) can acoustic anisotropy be explained by depositional layering?

\section{Velocity Anisotropy in Chalks and Limestones}

\section{Anisotropy in Chalks}

At the ooze/chalk transition, anisotropy profiles show tremendous changes (Fig. 2). In the ooze sections, values recorded are usually low (around 1\%-2\%) and positive, whereas in the chalk-limestone sections, anisotropy reaches absolute values as high as $20 \%$ with most of the values being negative in the chalk intervals (vertical values higher than horizontal values).

In chalk samples from DSDP Sites 62, 63, and 64, western equatorial Pacific, Gealy (1971) had previously found that samples having a horizontal $P$-wave velocity $<2.0 \mathrm{~km} / \mathrm{s}$ showed a higher vertical velocity than horizontal, whereas samples having a horizontal velocity $>2.0 \mathrm{~km} / \mathrm{s}$ showed a lower vertical velocity than horizontal. Gealy pointed out that "in semiconsolidated calcareous sediments, advecting fluids may create a vertical 'grain' which could account for this effect in low velocity calcareous sediments. Increased compac- 
tion may eventually destroy this vertical grain and crush the material into horizontal layers" (Gealy, 1971).

Looking at our Leg 130 data, however, it is puzzling to observe such a tremendous change in anisotropy profiles at the ooze/chalk limit chosen by the sedimentologists. As a matter of fact, the placement of the ooze/chalk transition is subjective and does not really correspond to a drastic change in sediment firmness. Rather, ooze to chalk transition has been shown to be a progressive change, with sediment firmness increasing over intervals of tens to hundreds of meters (Kroenke, Berger, Janecek, et al., 1991). We think, therefore, that the change in anisotropy profiles at about the ooze/chalk transition and the negative anisotropy values in chalk sections are an artifact caused by sediment disturbance rather than to a real change in lithology.

In chalk intervals, Urmos et al. (this volume) have noticed the greater scatter of laboratory velocities compared to in-situ velocity values recorded with logging tools. They concluded that laboratory velocity measurements made on chalk were affected by variable sample disturbance. The samples we used for laboratory velocity measurements, however, were carefully selected pieces of sediment that were apparently not affected by coring. Thus, instead of sampling disturbance caused by coring, we think that anomalous anisotropy values in the chalk sections reflect disturbances occurring during velocity measurements. In fact, changes in the anisotropy profiles arise at the exact location where we switched from DSV to the Hamilton Frame apparatus because of the sediment hardness. Contact between Hamilton Frame transducers and the sediment samples is obtained by lowering one of the transducers using a lead screw. With this system, the amount of uniaxial stress applied on the sediment sample is difficult to control and may be important enough to create small cracks in the sample. We actually made some macroscopic observations of such induced fracturing during $P$-wave velocity measurements with the Hamilton Frame. There is a chance that numerous samples were affected by microscopic cracking during $P$-wave velocity measurements.

In chalks, tensile strength measured for horizontal tension may be twice the tensile strength measured for vertical tension (Lind, 1988). Chalk is more sensitive to cracks along bedding planes than perpendicular to bedding. We think, therefore, that in chalk sections of Leg 130, higher vertical $P$-wave velocities than horizontal velocities are explained by the fact that we opened tensile cracks parallel to bedding planes during horizontal measurements whereas we did not open cracks during vertical measurements. Instead, we probably closed cracks that were opened during previous horizontal measurements (Fig. 12).

As seen previously, most of the anisotropy values in chalk are probably artifacts. It appears, however, that we can roughly correlate anisotropy profiles between holes at Site 805 (Fig. 13). We conclude that the amount of artificially induced velocity anisotropy is controlled to a certain extent by sediment composition or degree of cementation. Intervals of important negative anisotropy values may correspond to more weakly cemented or more layered sediment intervals where opening of cracks parallel to bedding is easier.

\section{Anisotropy in Limestones}

Eocene to Cretaceous limestone was drilled at Site 807 (Fig. 2). Induration of the sediment is such that cracking caused by the Hamilton Frame transducers does not affect $P$-wave velocity measurements as much as in the chalk interval. Except for some anomalous values, anisotropy is usually positive, ranging from $0 \%$ to $15 \%$ and increasing slightly with depth of burial. All our attempts to correlate anisotropy with index property changes (Carlson and Christensen, 1979) or carbonate content (Carlson et al., 1984) were unsuccessful. Further analyses are in progress to point out the potential causes of velocity anisotropy in these indurated calcareous sediments.
A

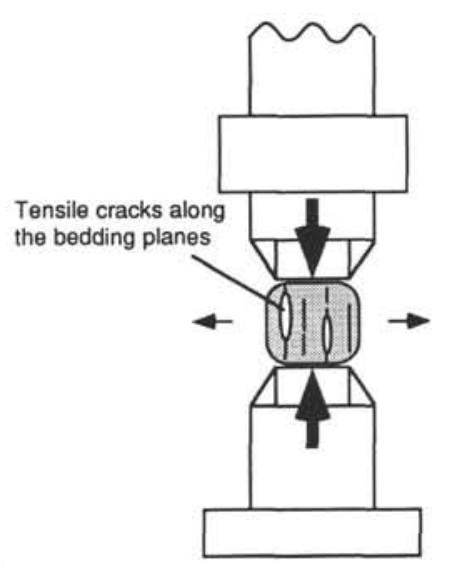

Horizontal P-wave measurement
B

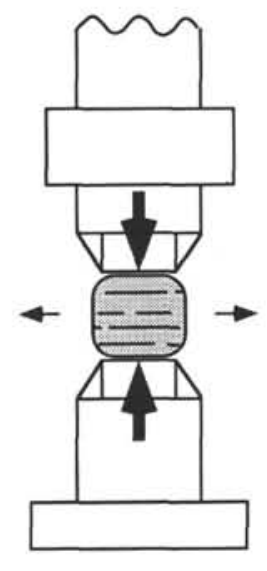

Vertical P-wave measurement

Figure 12. Chalk faulting between Hamilton transducers. Tensile cracks are opened parallel to bedding during horizontal $P$-wave velocity measurements, thus leading to anomalously low values (A); cracks are not created during vertical $P$-wave velocity measurements (B).

\section{CONCLUSIONS}

Acoustic anisotropy exists in calcareous oozes even at shallow depths of burial. Values are low, ranging from $-0.5 \%$ to $3.5 \% \pm 0.3 \%$ and averaging $1.2 \%$. Correlation of anisotropy profiles is possible between holes drilled at a same site, thus arguing for a lithologic control of acoustic anisotropy in ooze sections.

We discussed potential causes for acoustic anisotropy in ooze sections. It appears that

1. preferred orientation of calcite does not likely contribute to acoustic anisotropy in calcareous oozes from Leg 130;

2. alignment of elongate pores and cracks (the latter due to the release of overburden stress during core recovery) may account for a part of acoustic anisotropy measured but is not the major cause; and

3. according to Carlson et al. (1984), compositional layering in calcareous sediments must be regarded as the principal cause for acoustic anisotropy. In Leg 130 oozes, we suggest that anisotropy is not produced by the alternation of layers having different mineralogical composition but may be produced by the alternation, at small scale, of layers having different particle composition in terms of size and shape (for instance, alternation of foraminifer- and nannofossilrich layers). However, this hypothesis remains to be tested. Bioturbation affects all the ooze sections cored during Leg 130 and much of the original depositional features may have been removed.

Ooze to chalk transition is marked by a tremendous change in the anisotropy profiles. In chalk sections, absolute anisotropy values are higher (reaching 20\%) and most of the anisotropies are negative (horizontal $P$-wave velocities lower than vertical velocities). The chalk samples are affected by cracking when compressed by the Hamilton Frame transducers. Cracks occur along bedding planes during horizontal $P$-wave velocity measurements thus leading to anomalously low values.

\section{ACKNOWLEDGMENTS}

We thank the two reviewers M.H. Manghnani and R. Bachman, whose constructive criticisms helped to improve the manuscript. F.B. 
acknowledges funding from INSU/CNRS under DBT (Contribution No. 448 ) and IST programs. Shipboard $P$-wave velocity measurements were performed using a Digital Sound Velocimeter (DSV; Mayer et al., 1987) provided by the Département de Géologie Dynamique, Université Pierre et Marie Curie, and funded to Y. Lancelot by INSU/CNRS, France.

\section{REFERENCES}

Akal, T., 1972. The relationship between the physical properties of underwater sediments that affect bottom reflection. Mar. Geol., 13:215-266.

Bachman, R.T., 1979. Acoustic anisotropy in marine sediments and sedimentary rocks. J. Geophys. Res., 84:7661-7663.

Baker, D.W., and Carter, N.L., 1972. Seismic velocity anisotropy calculated for ultramafic minerals and aggregates. In Heard, H.C., Borg, I.V., Carter, N.L., and Raleigh, C.B. (Eds.), Flow and Fracture of Rocks. Am. Geophys. Union, Geophys. Monogr., 16:157-166.

Boyce, R.E., 1976. Definitions and laboratory techniques of compressional sound velocity parameters and water content, wet-bulk density, and porosity parameters by gravimetric and gamma ray attenuation techniques. In Schlanger, S.O., Jackson, E.D., et al., Init. Repts. DSDP, 33: Washington (U.S. Govt. Printing Office), 931-958.

Brocher, T.M., and Christensen, N.I., 1990. Seismic anisotropy due to preferred mineral orientation observed in shallow crustal rocks in southern Alaska. Geology, 18:737-740.

Carlson, R.L., 1981. Acoustic properties of limestones from the north-central Pacific, DSDP Leg 62. In Thiede, J., Vallier, T.L., et al., Init. Repts. DSDP, 62: Washington (U.S. Govt. Printing Office), 999-1004.

Carlson, R.L., and Christensen, N.I., 1977. Velocity anisotropy and physical properties of deep sea sediments from the western south Atlantic. In Perch-Nielsen, K., Supko, P.R., et al., Init. Repts. DSDP, 39: Washington (U.S. Govt. Printing Office), 555-559.

_ 1979. Velocity anisotropy in semi-indurated calcareous deep sea sediments. J. Geophys. Res., 84:205-211.

Carlson, R.L., Schaftenaar, C.H., and Moore, R.P., 1984. Causes of compressional-wave anisotropy in carbonate bearing deep-sea sediments. Geophysics, 49:525-532.

Crosson, R.S., and Lin, J., 1971. Voigt and Reuss prediction of anisotropic elasticity of dunite. J. Geophys. Res., 76:570-578.

Dandekar, D.P., 1968. Elastic constants of calcite. J. Appl. Phys., 39:2971-2973.

Gealy, E.L., 1971. Sound velocity, elastic constants, and related properties of marine sediments in the Western Equatorial Pacific: Leg 7, Glomar Challenger. In Winterer, E.L., Riedel, W.R., et al., Init. Repts. DSDP, 7 (Pt 2): Washington (U.S. Govt. Printing Office), 1105-1160.

Hamilton, E.L., 1970. Sound velocity and related properties of marine sediments, North Pacific. J. Geophys. Res., 75:4423-4446.

, 1974. Prediction of deep-sea sediments properties: state-of-the-Art. In Inderbitzen, A.L. (Ed.), Deep-sea Sediments: Physical and Mechanical Properties: New York (Plenum), 1-45.

, 1980. Geoacoustic modeling of the sea floor. J. Acoust. Soc. Am., 68:1313-1340.

Hamilton, E.L., Bachman, R.T., Berger, W.H., Johnson, T.C., and Mayer, L.A., 1982. Acoustic and related properties of calcareous deep-sea sediments. J. Sediment. Petrol., 52:733-753.

Heath, G.R., Burckle, L.H., et al., 1985. Init. Repts. DSDP, 86: Washington (U.S. Govt. Printing Office).

Johnson, T.C., Hamilton, E.L., and Berger, W.H., 1977. Physical properties of calcareous ooze: control by dissolution at depth. Mar. Geol., 24:259-277.

Kim, D.C., Katahara, K.W., Manghnani, M.H., and Schlanger, S.O., 1983. Velocity and attenuation anisotropy in deep-sea carbonate sediments. J. Geophys. Res., 88:2337-2343.

Kim, D.C., Manghnani, M.H., and Schlanger, S.O., 1985. The role of diagenesis in the development of physical properties of deep-sea carbonate sediments. Mar. Geol., 69:69-91.

Kroenke, L.W., Berger, W.H., Janecek, T.R., et al., 1991. Proc. ODP, Init. Repts., 130: College Station, TX (Ocean Drilling Program).

Lind, I., 1988. Stylolite formation [Ph.D. dissert.]. Danmarks Tekniske Højskole, Denmark.
Mayer, L.A., Courtney, R.C., and Moran, K., 1987. Ultrasonic measurements of marine sediment properties. Proc. Oceanogr., 87:1-139

Milholland, P., Manghnani, M.H., Schlanger, S.O., and Sutton, G.H., 1980. Geoacoustic modeling of deep-sea carbonate sediments. J. Acoust. Soc. Am., 68:1351-1360.

Nur, A., 1971. Effects of stress on velocity anisotropy in rocks with cracks. J. Geophys. Res., 76:2022-2034.

Ruddiman, W.F., Cameron, D., and Clement, B.M., 1987. Sediment disturbance and correlation of offset holes drilled with the hydraulic piston corer: Leg 94. In Ruddiman, W.F., Kidd, R.B., Thomas, E., et al., Init. Repts. DSDP, 94, Pt. 2: Washington (U.S. Govt. Printing Office), 615-634.

Schaftenaar, C.H., and Carlson, R.L., 1984. Calcite fabric and acoustic anisotropy in deep-sea carbonates. J. Geophys. Res., 89:503-510.

Date of initial receipt: 4 September 1991

Date of acceptance: 24 August 1992

Ms 130B-041

\section{Velocity anisotropy (\%)}

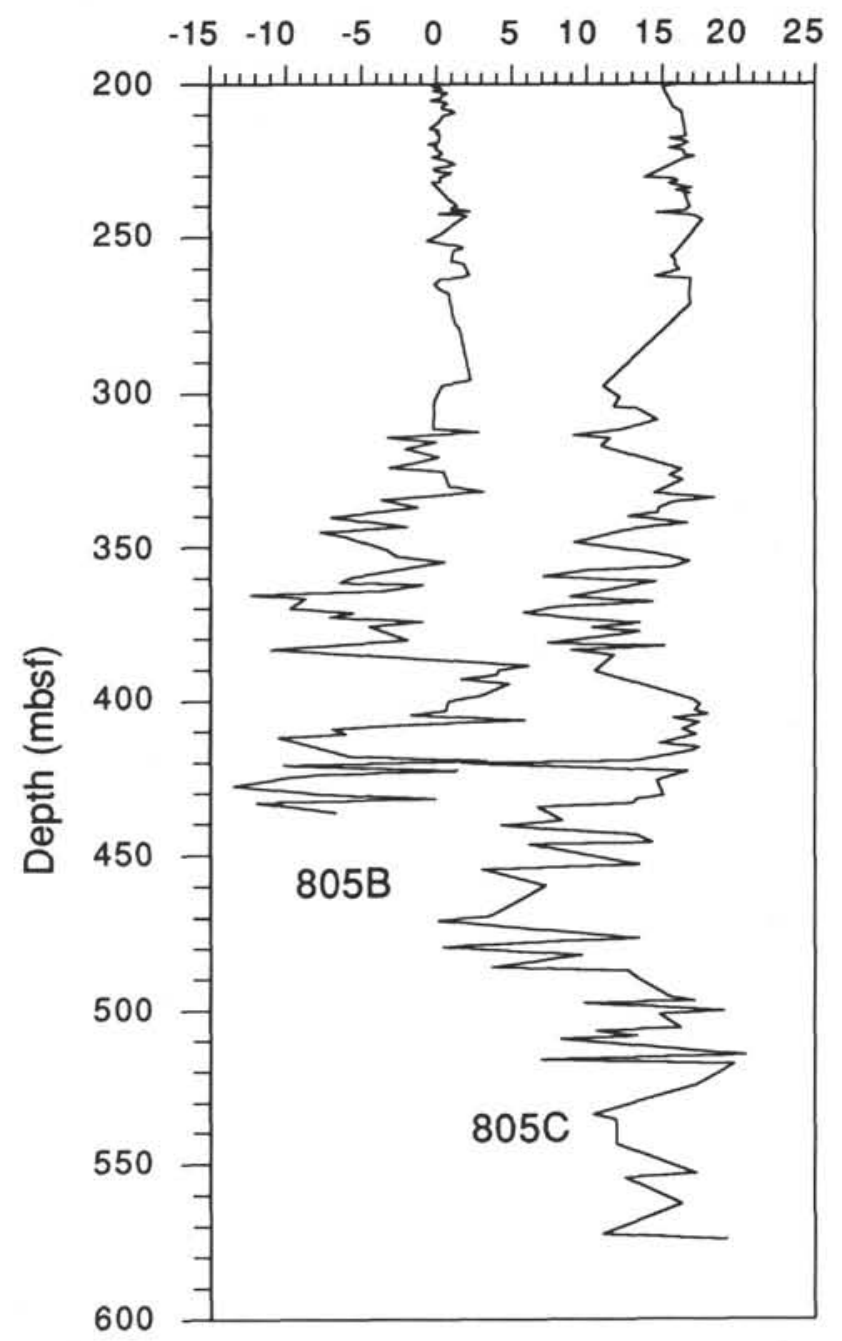

Figure 13. Velocity anisotropy in chalk section, Holes $805 \mathrm{~B}$ and $805 \mathrm{C}$. Profile for Hole $805 \mathrm{C}$ is offset by $15 \%$. 